\title{
Intrahepatic Cholestasis of Pregnancy and Cancer: A Cohort Study
}

Suvi-Tuulia Hämäläinen ${ }^{1,2^{*}}$, Kaisa Turunen ${ }^{1}$, Kari J Mattila ${ }^{1}$, Elise Kosunen ${ }^{1,3}$ and Markku Sumanen ${ }^{1}$

${ }^{1}$ Department of General Practice, Faculty of Medicine and Life Sciences, University of Tampere, Tampere, Finland

2 Janakkala Health Centre, Turenki, Finland

${ }^{3}$ Centre for General Practice, Pirkanmaa Hospital District, Tampere, Finland

"Corresponding author: Suvi-Tuulia Hämäläinen, Department of General Practice, Faculty of Medicine and Life Sciences, University of Tampere, Tampere, Finland, Tel: +358368011; E-mail: hamalainen.suvi.t@student.uta.fi

Received date: June 05, 2017; Accepted date: June 22, 2017; Published date: July 3, 2017

Copyright: @ 2017 Hämäläinen ST, et al. This is an open-access article distributed under the terms of the Creative Commons Attribution License, which permits unrestricted use, distribution, and reproduction in any medium, provided the original author and source are credited.

\section{Abstract}

Objective: In a previous questionnaire study, more breast cancers were reported by women with intrahepatic cholestasis of pregnancy (ICP) than by the controls. The aim of this study was to establish whether ICP is associated with cancer in the Finnish Cancer Registry data, the study population being the same cohort as in the questionnaire study.

Methods: The study population comprised 571 women with ICP in at least one pregnancy and 1,333 controls from Tampere University Hospital in Finland during 1969-1988. The cancer data were obtained from the Finnish Cancer Registry. The cancers were classified by ICD-O-3 and diagnosed during the period 1953-2013.

Results: In the ICP group, the odds ratio of cancers (OR 1.26, 95\% Cl 0.96-1.64), and breast cancer in particular (OR 1.36, 95\% Cl 0.91-2.03), was slightly higher than in the control group. Seven percent of the ICP group and $5.3 \%$ of the control group had breast cancer.

Conclusion: Based on this study there is not a significant association between ICP and cancer. Earlier observation in the questionnaire study regarding association between ICP and breast cancer cannot be confirmed by this registry based study.

Keywords Intrahepatic cholestasis of pregnancy; ICP; Cancer

\section{Introduction}

Intrahepatic cholestasis of pregnancy (ICP) is a reversible liver disorder with pruritus as the main symptom, especially on the palms and soles. An elevated serum bile acid and transaminase concentration is also required for diagnosis [1]. In Europe, the incidence of ICP is approximately $1 \%$, but rates vary geographically [2]. In Finland, the incidence is approximately $1.0-1.5 \%$ [3] and in Sweden the incidence is $0.5-0.75 \%$ [4]. Hormonal factors seem to contribute to the pathogenesis of ICP [5,6]. Estrogen may participate in the development of cholestasis [7] and progesterone may impair hepatic bile homeostasis [8]. Genetic factors are known to be involved in the pathogenesis; ICP is inherited as a sex-limited dominant phenotype and multiple genes are influential [9]. Multidrugresistant protein 3 (MDR3) is associated with up to $15 \%$ of ICP cases [10,11]. Environmental factors may also have a role in the pathogenesis of the disorder [12]. In addition, a positive family history [13] and twin pregnancies raise the risk of ICP [14].

Excessive exposure of endogenous estrogen over the lifetime may be a causative factor of breast cancer [15]. Hormonal, genetic, and environmental factors are known to have an impact on the aetiology and pathogenesis of cancers and ICP. Cancer antigen 15-3 (CA15-3) is a glycoprotein commonly found in breast cancer cells, and its levels in serum reflect the amount of breast cancer cells in the body. CA15-3 levels are raised during pregnancy in general, but they are higher in
ICP pregnancies than in controls [16]. In an extensive registry-based study, ICP was associated with an increased risk for later hepatobiliary cancer. Hepatitis $C$ infection was strongly associated with liver cancer, but after adjusting for this diagnosis, women with ICP were still at increased risk for liver malignancy. In addition, in a separate analysis excluding all women with gallstone disease or cholangitis, women with ICP had an increased risk for biliary tree malignancies [17].

A low number of child births has been associated with an increased risk for breast cancer. Since mothers with ICP have been found to limit their child number more often than controls [18], it may be speculated whether this has increased the incidence of breast cancers. Primary healthcare arranges almost exclusively maternity care in the Nordic countries [19]. In Finland health centres maintain maternity health clinics where a nurse or a midwife and a Family Doctor are responsible for care [20]. The maternity health clinics in primary health care usually detect ICP. If a pregnant woman complains of pruritus her ALAT and bile acids values are screened. Either of these values being elevated the mother is referred to an obstetrician [21]. If pruritus is intolerable the mother is referred to the obstetric clinic without waiting the results of the blood test.

A questionnaire study observed that ICP may be associated with an elevated risk for breast cancer [22]. However, the study was based on subjective information obtained from self-reports. The aim of the present study was to investigate, using objective registry data, whether ICP has an association with breast cancer or other cancers when using the same cohort as the questionnaire study. 
Page 2 of 4

\section{Material and Methods}

All ICP pregnancies at Tampere University Hospital (TUH) during 1969-1988 were collected from the patient records. From 1969 to 1986 , ICD-8 was used at TUH. Because ICD-8 did not include a precise code for ICP, we checked all the obstetric codes that might contain ICP: 637.9 Toxicosis NUD, 639.00 Pruritus, 639.01 Icterus gravis, 639.09 Necrosis acuta et subacuta hepatis, and 639.98 Aliae definitae. Thereafter, we checked the written diagnosis behind the code, and if it referred to ICP, we included the case for further selection. ICD-9 was used between 1987 and 1988, and it contained the appropriate codes 6467A Hepatosis gravidarum and 6467X Hepatopathia alia. The diagnosis was verified from each patient record with the presence of the main symptom of itching and abnormal laboratory test results. At least one of the following was required: ASAT $>35$ U/l, ALAT $>40 \mathrm{U} / \mathrm{l}$, or bile acids $6 \mu \mathrm{mol} / \mathrm{l}$ or more.

The study population comprised 687 ICP deliveries. The data included some women with repeated ICP deliveries and each of these women was studied as an individual case. The ICP group thus contained 575 women. The proceeding and following subjects in the maternity ward diary were taken as controls for each ICP case. There were 1,374 controls in total. The groups were comparable regarding age, educational level, and body mass index. The deliveries of mothers with ICP took place at earlier gestational weeks than those of the controls. Four women were ruled out from the ICP cases and 41 from the controls because of a missing personal identity code. The final data comprised 571 women with ICP and 1,333 controls.

The cancer data were obtained from the Finnish Cancer Registry in January 2014 based on personal identity codes. All physicians, hospitals, and other relevant institutions have had an obligation to report every cancer to the Finnish Cancer Registry since 1961. The database contains all the diagnosed cancers and cancer deaths in Finland since 1961 and the most of cancers since 1953, when systematic cancer registration was started [23]. The Finnish Cancer Registry also contains information on all death certificates that mention cancer. The Registry takes notice of the completeness and accuracy of its data, and its completeness has been shown to be over 99\% [24]. The Registry is upheld by the National Institute for Health and Welfare of Finland. The study data included all reported cancers of the cohort during 1953-1960, all registered cancers during 1961-2013, and the location and behaviour of the cancer. The cancers were reported by ICD-O-3 topographical codes [25]. Women who had had more than one cancer were also included in the study. The cancers were classified by ICD-O-3 codes into larger subgroups. Cancer behaviour was classified as benign, unclear behaviour, carcinoma in situ, or malignant.

The data were analysed using the SPSS System for Windows, Version 22.0. The results are presented as frequencies and percentages. Statistical significance was tested with a chi-squared test. Binary logistic regression analysis was performed to obtain odds ratios (OR) and $95 \%$ confidence intervals $(\mathrm{CI})$. The dependent variable was "ICP or not". T-test was performed to explore difference regarding age at the diagnose moment of cancer. The cohort did not obtain informed consent because the study is retrospective and does not have an effect on treatment. The study has the approval of the Regional Ethics Committee of Tampere University Hospital (R02149) and the National Institute for Health and Welfare in Finland (THL/1051/5.05.00/2014).

\section{Results}

In the ICP group, 96 women (16.8\%) had been diagnosed with at least one cancer, compared to 185 women (13.9\%) in the control group. The difference was not statistically significant $(\mathrm{p}=0.098)$. Mothers with ICP had a slightly higher risk for cancer (OR 1.26, 95\% CI 0.96-1.64) than the control mothers. None of the mothers with ICP and fifteen $(1.1 \%)$ of the controls had been diagnosed with two or more separate cancers $(\mathrm{p}=0.011)$. One of the controls had had three separate cancers. Three women had been diagnosed with a cancer before labour and all of them were controls.

The occurrence of cancers is presented in Table 1. Breast cancer was the most common cancer in both groups. The mothers with ICP had a slightly higher risk for breast cancer (OR 1.36, 95\% CI 0.91-2.03) than the control mothers. Breast cancer was diagnosed at a slightly older age in the ICP group than in the control group but the difference was not statistically significant.

\begin{tabular}{|c|c|c|c|c|c|c|c|}
\hline \multirow[t]{2}{*}{$\begin{array}{l}\text { ICD-10 } \\
\text { code }\end{array}$} & \multirow[t]{2}{*}{ Cancer } & \multicolumn{2}{|c|}{$\begin{array}{l}\text { Mothers } \\
\text { with ICP } \\
n=571\end{array}$} & \multicolumn{2}{|c|}{$\begin{array}{l}\text { Control } \\
\text { mothers } \\
n=1,333\end{array}$} & \multicolumn{2}{|c|}{ Difference } \\
\hline & & $\mathrm{n}$ & $\%$ & $\mathrm{n}$ & $\%$ & $\begin{array}{l}\% \\
\text { units }\end{array}$ & $\begin{array}{l}\mathrm{p}- \\
\text { value }\end{array}$ \\
\hline C50 & Breast & 40 & 7.0 & 70 & 5.3 & 1.7 & 0.133 \\
\hline $\begin{array}{l}\text { C73- } \\
\text { C75 }\end{array}$ & $\begin{array}{l}\text { Thyroid and other } \\
\text { endocrine glands }\end{array}$ & 6 & 1.1 & 5 & 0.4 & 0.7 & 0.075 \\
\hline $\begin{array}{l}\text { C64- } \\
\text { C68 }\end{array}$ & Urinary tract & 4 & 0.7 & 3 & 0.2 & 0.5 & 0.116 \\
\hline $\mathrm{C} 42$ & $\begin{array}{l}\text { Haematopoietic and } \\
\text { reticuloendothelial } \\
\text { systems }\end{array}$ & 2 & 0.4 & 2 & 0.2 & 0.2 & 0.382 \\
\hline $\begin{array}{l}\text { C30- } \\
\text { C39 }\end{array}$ & $\begin{array}{l}\text { Respiratory and } \\
\text { intrathoracic organs }\end{array}$ & 1 & 0.2 & 3 & 0.2 & 0.0 & 0.827 \\
\hline $\begin{array}{l}\text { C40- } \\
\text { C41 }\end{array}$ & $\begin{array}{l}\text { Bone and articular } \\
\text { cartilage }\end{array}$ & 1 & 0.2 & 3 & 0.2 & 0.0 & 0.827 \\
\hline $\mathrm{C} 80$ & Unknown primary site & 1 & 0.1 & 1 & 0.1 & 0.0 & - \\
\hline $\begin{array}{l}\text { C00- } \\
\text { C14 }\end{array}$ & $\begin{array}{l}\text { Lip, oral cavity, and } \\
\text { pharynx }\end{array}$ & 0 & 0.0 & 1 & 0.1 & -0.1 & 0.513 \\
\hline $\begin{array}{l}\text { C15- } \\
\text { C26 }\end{array}$ & Digestive organs & 7 & 1.2 & 19 & 1.4 & -0.1 & 0.731 \\
\hline $\begin{array}{l}\text { C45- } \\
\text { C49 }\end{array}$ & $\begin{array}{l}\text { Mesothelial and soft } \\
\text { tissue }\end{array}$ & 0 & 0.0 & 1 & 0.1 & -0.1 & 0.513 \\
\hline $\begin{array}{l}\text { C43- } \\
\text { C44 }\end{array}$ & $\begin{array}{l}\text { Melanoma and other } \\
\text { malignant neoplasms of } \\
\text { skin }\end{array}$ & 18 & 3.2 & 38 & 2.9 & -0.1 & 0.721 \\
\hline $\begin{array}{l}\text { C51- } \\
\text { C58 }\end{array}$ & Female genital organs & 14 & 2.5 & 35 & 2.6 & -0.1 & 0.826 \\
\hline $\begin{array}{l}\text { C69- } \\
\text { C72 }\end{array}$ & $\begin{array}{l}\text { Eye, brain, and other } \\
\text { parts of central nervous } \\
\text { system }\end{array}$ & 3 & 0.5 & 8 & 0.6 & -0.1 & 0.844 \\
\hline C77 & Lymph nodes & 2 & 0.4 & 7 & 0.5 & -0.1 & 0.610 \\
\hline
\end{tabular}

Table 1: The occurrence of cancers in mothers with ICP and the controls. 
Melanoma and other malignant neoplasms of the skin as well as cancers of the female genital organs were among the most common cancers in both groups. Cancers of the thyroid and other endocrine glands and urinary tract cancer were more common in the mothers with ICP than in the controls, but the differences were not statistically significant. Of the digestive organ cancers, hepatobiliary cancer was also examined separately. Hepatobiliary cancer was found in one mother with ICP and among none of controls. Most of the cancers (nearly 90\%) were malignant in both groups (Table 2). The difference between the groups was not statistically significant $(\mathrm{p}=0.758)$.

\begin{tabular}{|l|l|l|}
\hline Cancer behaviour & Mothers with ICP (n=96) (\%) & Control mothers (n=185) (\%) \\
\hline Malignant & 87.5 & 86.5 \\
\hline Carcinoma in situ & 6.3 & 5.4 \\
\hline Unclear behaviour & 0.0 & 1.1 \\
\hline Benign & 6.3 & 7.0 \\
\hline
\end{tabular}

Table 2: Cancer behaviour according to ICD-O-3 among mothers with ICP and the controls.

The mothers with ICP had been diagnosed with cancer at a slightly older age, the mean age being 53.0 years in the ICP group and 51.8 years in the control group. The difference was 1.2 years $(\mathrm{p}=0.315)$. The mean age of mothers who had not been diagnosed with cancer was 61.5 years among ICP mothers and 61.3 years among controls in $31 / 12 / 2013$.

\section{Discussion}

The ICP group and the control group evinced minor differences in most of the study outcome measures. The findings are in agreement with former observations on the association of cancer and ICP. In the control group, there were women who had been diagnosed with two or more separate cancers, but in the ICP group each woman with cancer had been diagnosed with only one cancer. ICP was associated with a slightly higher risk for cancer, especially breast cancer.

The aim of the present study was to establish whether ICP is associated with an increased risk for cancers, and especially for breast cancer, which was the result found from the earlier study based on selfreports. Despite the small loss of cases, the data were adequate. The data obtained from the Finnish Cancer Registry can be considered reliable.

Medications may have an impact on the risk for cancer. Over the past decades, various treatments have been used for ICP. We have not collected information about the medication for ICP among our study population, and consequently the role of medication regarding the risk for cancer cannot be evaluated.

A recent Swedish study did not find any clear association between overall cancer and ICP [17], which is in agreement with our findings. In the same study, an increased risk for later hepatobiliary cancer in women with ICP was found (liver cancer: HR 3.61; and biliary tree cancer: HR 2.62). In the aforementioned study, the occurrence of hepatobiliary cancers was small in the ICP group (0.1-0.2\%). Based on the above study, the expectation value to find any hepatobiliary cancers in our study was very small. However, one hepatobiliary cancer was found in our ICP group, which exceeds the expectation value.

There is higher risk of hepatobiliary disease and particularly chronic hepatitis among women with a history of ICP $[26,27]$. The latter disease causes liver cirrhosis and is often complicated by hepatocellular cancer[17]. Also cholelithiasis and chronic cholangitis are associated with ICP [26,27] and are associated with gallbladder and cholangiocellular cancer[17].
The Swedish registry study did not find any association between breast cancer and ICP (HR 1.03). In our study, mothers with ICP had a slightly higher risk for breast cancer than the control mothers (OR 1.36), although the difference was not statistically significant. The occurrence of breast cancer was lower in the Swedish population (1.6\%) than in our Finnish population. Women's risk for having breast cancer before the age of 75 is $9.9 \%$ in Finland and 9.6\% in Sweden [28]. Our longer follow-up time and the younger age of mothers in the Swedish study might explain the difference. Nevertheless, the cohort should be followed even longer because now the cohort represents those who had been diagnosed with cancer at a fairly young age.

Premature delivery (gestation weeks <37) seems to increase the mother's risk for breast cancer later in life [29]. Formerly, it has been found that ICP is associated with an elevated risk for delivery in gestation weeks under 37 [14]. It can be considered that premature delivery may increase the number of breast cancer cases among ICP women.

A questionnaire study observed that the women with ICP reported more breast cancer ( $6.3 \%$ vs. $3.7 \%, p=0.047)$ [22]. In our study, breast cancer was found among $7.0 \%$ in the ICP group and among $5.3 \%$ in the control group, the cohort being the same as in the questionnaire study. In this registry study, however, the difference between the groups is not statistically significant.

ICP has found to have a multifactorial genetic base. It may be speculated that ICP is one expression of a larger group of genetic diseases. Hormonal factors may be relevant in the pathogenesis of ICP and breast cancer $[5,6,15]$. It may be speculated whether the same hormonal factors have an effect on both diseases.

This is the first Finnish registry study on the potential association between ICP and cancer. According to the writers' knowledge there is only one registry based study investigating the association between ICP and cancer [17], and therefore the findings in this study may be considered unique. However, former observations regarding the association between ICP and breast cancer in the questionnaire study could not be confirmed by this registry based study. A larger number of ICP women and a longer follow-up time of the cohort might be needed to confirm the results. Based on this study doctors do not have to change their treating strategies and screen cancers because a woman has a history of ICP. 


\section{Acknowledgments}

The Centre for General Practice of the Pirkanmaa Hospital District funded the study by settling the dues from the National Institute for Health and Welfare in Finland and the Finnish Cancer registry. We are grateful to the National Institute for Health and Welfare in Finland and the Finnish Cancer Registry for their consent to use the registry data.

\section{Conflict of Interest}

The authors have no conflicts of interest.

\section{References}

1. Williamson C, Geenes V (2014) Intrahepatic cholestasis of pregnancy. Obstet Gynecol 124: 120-133.

2. Geenes V, Williamson C (2009) Intrahepatic cholestasis of pregnancy. World J Gastroenterol 15: 2049-2066.

3. Laatikainen T, Tulenheimo A (1984) Maternal serum bile acid levels and fetal distress in cholestasis of pregnancy. Int J Gynaecol Obstet 22: 91-94.

4. Wikström Shemer E, Marschall HU, Ludvigsson JF, Stephansson O (2013) Intrahepatic cholestasis of pregnancy and associated adverse pregnancy and fetal outcomes: a 12-year population-based cohort study. BJOG 120: 717-723.

5. Reyes H (1997) Review: Intrahepatic cholestasis. A puzzling disorder of pregnancy. J Gastroenterol Hepatol 12: 211-216.

6. Reyes H (2008) Sex hormones and bile acids in intrahepatic cholestasis of pregnancy. Hepatology 47: 376-379.

7. Simon FR, Fortune J, Iwahashi M, Gartung C, Wolkoff A et al(1996) Ethinyl estradiol cholestasis involves alterations in expression of liver sinusoidal transporters. Am J Physiol 271: G1043-52.

8. Abu-Hayyeh S, Papacleovoulou G, Lovgren-Sandblom A, Tahir M Oduwole O, et al. (2013) Intrahepatic cholestasis of pregnancy levels of sulfated progesterone metabolites inhibit farnesoid $\mathrm{X}$ receptor resulting in a cholestatic phenotype. Hepatology 57: 716-726.

9. Dixon PH, Williamson C. (2016) The pathophysiology of intrahepatic cholestasis of pregnancy. Clin Res Hepatol Gastroenterol 40: 141-153.

10. Pan C, Perumalswami PV (2011) Pregnancy-related liver diseases. Clin Liver Dis 15: 199-208.

11. Poupon R (2005) Intrahepatic cholestasis of pregnancy: from bedside to bench to bedside. Liver Int 25: 467-468.

12. Turunen K, Helander K, Mattila KJ, Sumanen M (2013) Intrahepatic cholestasis of pregnancy is common among patients' first-degree relatives. Acta Obstet Gynecol Scand 92: 1108-1110.

13. Eloranta ML, Heinonen S, Mononen T, Saarikoski S (2001) Risk of obstetric cholestasis in sisters of index patients. Clin Genet 60: 42-45.
14. Turunen K, Sumanen M, Haukilahti RL, Kirkinen P, Mattila K (2010) Good pregnancy outcome despite intrahepatic cholestasis. Scand J Prim Health Care 28: 102-107.

15. Yager JD, Davidson NE (2006) Estrogen carcinogenesis in breast cancer. N Engl J Med 354: 270-282.

16. Sharma JB, Sharma S, Usha BR, Gupta A, Kumar S, et al. (2015) A crosssectional study of tumor markers during normal and high-risk pregnancies. Int J Gynaecol Obstet 129: 203-206.

17. Wikström Shemer EA, Stephansson O, Thuresson M, Thorsell M, Ludvigsson JF, et al. (2015) Intrahepatic cholestasis of pregnancy and cancer, immune-mediated and cardiovascular diseases: A populationbased cohort study. J Hepatol 63: 456-461.

18. Mölsä A, Turunen K, Mattila KJ, Sumanen M (2012) Unnecessary confusion about family planning after intrahepatic cholestasis of pregnancy. Contraception 86: 639-644.

19. Sigurdsson JA (2003) The GP's role in maternity care. Scand J Prim Health Care 21:65.

20. Laes E, Gissler M (2006) Health in Finland: Health of pregnant women. Ministry of Social Affairs and Health, Finland.

21. Duodecim (2016) Evidence-based medicine guidelines, Cholestasis of pregnancy (hepatosis).

22. Turunen K, Mölsä A, Helander K, Sumanen M, Mattila KJ (2012) Health history after intrahepatic cholestasis of pregnancy. Acta Obstet Gynecol Scand 91: 679-685.

23. Finnish Cancer Registry. http://www.cancer.fi/syoparekisteri/en/ registration/. Referred 30.5.2017.

24. Teppo L, Pukkala E, Lehtonen M (1994) Data quality and quality control of a population-based cancer registry: Experience in Finland. Acta Oncol 33: $365-369$.

25. World Health Organization (2015). http://www.who.int/ classifications/icd/adaptations/oncology/en/. Referred 30.5.2017.

26. Marschall HU, Wikström Shemer E, Ludvigsson JF, Stephansson O (2013) Intrahepatic cholestasis of pregnancy and associated hepatobiliary disease: a population-based cohort study. Hepatology 58: 1385-1391.

27. Ropponen A, Sund R, Riikonen S, Ylikorkala O, Aittomäki K (2006) Intrahepatic cholestasis of pregnancy as an indicator of liver and biliary diseases: A population-based study. Hepatology 43: 723-728.

28. Engholm G, Ferlay J, Christensen N, Kejs A, Hertzum-Larsen R, et al. (2016) NORDCAN: Cancer Incidence, Mortality, Prevalence and Survival in the Nordic Countries, Version 7.3. Association of the Nordic Cancer Registries. Danish Cancer Society.

29. Hsieh CC, Wuu J, Lambe M, Trichopoulos D, Adami HO, et al. (1999) Delivery of premature newborns and maternal breast-cancer risk. Lancet 353: 1239. 